\title{
Lessons learnt on implementing project management in a functionally- only structured South African municipality
}

\author{
C.J. Brown* and M.C. Botha \\ University of Stellenbosch Business School, University of Stellenbosch, \\ PO Box 610, Bellville 7535, Republic of South Africa \\ cjb2@usb.sun.ac.za
}

Received August 2005

\begin{abstract}
This paper reports on the most important lessons learnt from the implementation of project management in a South African district municipality. These lessons demonstrate how difficult it is to gain acceptance of project management in an organisation; more specifically when it has no previous exposure to integrative cross-functional structures and work methods. The paper aims to create awareness that organisations should not jump into project management precariously, but with a well developed project plan. This is done through the discussions of a dozen problematic situations that surfaced during the case, as well as the corrective actions that were taken. Some of these problems were indeed confirmations of the implementation team's research during the preparatory phase of the implementation project. Although the implementation of project management was found to be not well researched, such research is highlighted were applicable. These problematic situations varied widely. The most important ones to address included inter alia, that the implementation should be a project in own right, a need for firm top management commitment, a strong resistance to change that was encountered, having to deal with the challenges to the de facto organisational culture, structure and systems, the need to establish security for clear career paths in project management, and the necessity for a sound and supportive change management process.
\end{abstract}

*To whom all correspondence should be addressed.

\section{Introduction}

\section{Purpose of the paper}

This paper is primarily addressed at the decision makers about project management in an organisation. In the arenas of business and management, the principles of project management are relatively simple and much of it actually common sense. However, this case study confirmed that the implementation and acceptance thereof, in a functionallyonly structured organisation, is quite a complex process. The paper's prime purpose is therefore to highlight, that after the decision to implement project management is made, a number of not so obvious implications for the organisation, as well as structural, organisational culture and systems changes, have to be thoroughly managed to ensure success.

\section{Importance of the paper}

The paper does not address project management as such, but rather the problems encountered when project management is implemented in a hitherto functionally-only structured organisation. The value of the paper lies in the presentation of the lessons learnt and the strategy and principles that were developed. Although some research on some of the aspects were found during the literature survey, only scant evidence could be found of an integrative approach to an implementation process. The growing awareness of project management as a method for service provision, has become noticeable at all levels of government in South Africa. The authors view that as justification for this paper and for further research, so that the experiences encountered here, may develop into a generalised approach for future similar endeavours in similar organisations.

\section{How the research and the paper was generated}

The paper extracts information from a comprehensive literature study that was performed for an MBA thesis (Botha, 2003). Training in operational project management was given to councillors as well as middle to senior management officials of the municipality in case. During this, several unfavourable perceptions as well as an organisation culture quite unfamiliar with and even hostile to the notion of cross-functional management, was uncovered. This led to extensive discussions and interviews with a representative sample of the affected persons. The outcome of these discussions influenced the actions that were to be included in the design of the implementation process. The implementation plan also built on two previous implementations of project management in other organisations that one of the authors had been involved with. Fourthly a Project Management Steering Group was formed within the organisation that had high level ownership for the implementation plan, under the mentorship of one of the authors. From several interactions with this group the authors drew a number of inferences which also contributed to this report. 


\section{Overview of project management}

Experience has shown that the high level decision makers, in organisations with a functional organisation tradition, are typically not knowledgeable about project management. That leads to two issues to address. The first is to establish common understanding of the basic principles of project management, and the second is to expound the ground rules for implementing, and later, for applying project management successfully in an organisation.

With reference to the first issue, a project can be defined as 'that ad-hoc set of activities with logical relationships, that is executed by a specific team, to achieve a one-off, specified goal within planned performance, time and cost targets' (Brown, 2004: 9). Project management can be defined as "the set of management techniques applied, to enable the integrated management of the performance, time, cost and human relations frameworks pertaining to a project, to achieve the goal(s) of the project (Brown, 2004: 10). Relating to these definitions, the management of a project can generically be reduced to solving the four questions of what is to be produced by this project?, who are going to do the work and with what resources?, how much time is required?, and how much money is required? From integrating various opinions in the literature, the project way of management appears to be founded on four foundations, viz:

1. Kerzner (1992: 69-92) argues a clear case that a project behaves like and emulate a system. The consequence of that statement is that in the analysis, planning and management of a project, the systems approach to management should be followed. That has the following implications for the development of a project management theory:

- a holistic approach to the deliverable of the project should be followed;

- $\quad$ a system, i.e. a project, can be broken down into its elements (the parts of a project), provided the interrelationships between the elements are known and honoured;

- $\quad$ a system, i.e. a project, is the product of the interaction between its parts; and

- $\quad$ synergy can be achieved through the integrated actions (referring to team work) of a system's constituent parts.

2. Reiss (1992: 16-21), representative of the opinions of many authors, states that due to the requirement that a project should have cost and time targets, successful project execution is entirely dependent on thorough preplanning of the courses of action to be followed, as well as measures to keep to the planned courses of action.

3. Kerzner (1992: 6) points out that the scope, cost and duration of a project are inherently interdependent and must therefore be planned and managed integratedly.
These interdependent relationships have a marked influence on how projects are planned.

4. As expounded by Kezsbom and Edward (2001: 47-64) and Ford and Randolph (1992: 271), once again representative of virtually all authors, project management is inherently a derivative of the matrix approach to organisation, and therefore embraces cross-functional organisational structures.

The second issue is addressed by inter alia Morrison and Brown (2004: 73-94), who conceptualised a construct for project management effectiveness. From this construct can be inferred that an organisation must comply with five conditions, for its project management to operate effectively, as follows:

1. An organisation wide strategy for project management must be initiated and supported by top management. Brown (1999) and Tettemer (1991) assert that a strategy is essential, because it is a prerequisite for the displacement of traditional relationships and practices with new ones. It should also serve to comfort top administrators during the period of change. It should also demonstrate the validity of the project management process and top management's belief in it. For project managers there should be consistency about the effect and cause relationship of their decisions, which only a well-structured strategy and resulting policies can provide.

2. An organisational culture supportive of project management must be inculcated in the organisation. The successful management of a project depends usually on the successful integration of multifunctional resources. In most cases such inputs are organised by way of an ad-hoc matrix organisation that cuts horizontally across the natural (vertical) inclinations of the incumbents of the said functions. In Brown (2000: 5) it is argued that a project management enabling or supporting organisational culture differs sufficiently from the culture of functional structures, so that the success of the application of project management will be enhanced by engendering such a culture in previously functionally structured organisations. This is confirmed by Bonelli (1998: 11), who very aptly states: 'The structure of the organisation, and therewith its project management culture, has a profound effect on the ability of the project management discipline to thrive and develop'.

3. It must be recognised that the projects of a sizeable organisation are not of a singular nature, but possess different characteristics that can be portrayed on a continuum from simple to complex. An appropriate management role must therefore be allocated to the project leader with reference to the type, size and complexity of the project. By implication a continuum of such management roles, project management organisation structures and styles, and levels of authority for the project leader, for the execution of the organisation's projects must be designed. That boils down to fit the project management methodology to 
the project, and not vice versa. This is also congruent with the view of Ford and Randolph (1992: 271, 272, 282) that specific cross-functional structures must be developed for the specific products to be produced.

4. Appropriate systems for the facilitation of the project management processes must be provided. However, the prevalent systems in an organisation are invariably not orientated to the needs of project administration. In line with the previous point, these systems can also not be of a singular nature and capacity. Therefore careful selection of systems appropriate for an organisation's array of projects needs to be done. These must also be compatible with the existing financial and administrative systems of the organisation. (Brown, 1999: 1 - 3).

5. Project leaders must be skilled in the various project management techniques. One of the primary tasks of project leaders is to facilitate the project management process (Brown, 2004: 19). Very few project leaders, however, start their careers in project management, but almost always in a functional skill. Training in the project management philosophies, principles and techniques is thus vital.

\section{The municipal structure in South Africa}

As directed by the Constitution of the Republic of South Africa, 1996, the Local Government: Municipal Structures Act, 1998, organizes all municipalities in South Africa into three categories, viz:

- Category A (metropolitan) municipalities that have exclusive municipal legislative and executive authority in its area. In practice these were formed by the amalgamation of a number of previously independent neighbouring municipalities into one (big) municipality;

- $\quad$ Category B (local) municipalities that share some of its municipal legislative and executive authority with a category $\mathrm{C}$ municipality within whose area it falls; and

- Category C (district) municipalities that have municipal legislative and executive authority in an area that includes more than one category B municipality, with whom they share some of their municipal legislative and executive authority. To this end a prescribed portion of the councillors of all the $\mathrm{B}$ municipalities in a C municipality's area, are also councillors of the $\mathrm{C}$ municipality. (Botha, 2003: 1).

District municipalities are primarily responsible for capacity building (including project management), bulk or regional infrastructure and district-wide planning. District councils also render technical and administrative services to communities in their area that haven't developed into B category municipalities yet. South Africa presently has 6 metropolitan or category A, 231 local or category B, and 47 district or category $C$ municipalities, although the numbers can change over time. Each of these municipalities are organized into directorates congruent with their own circumstances and needs, and each directorate renders its own specific specialist services and skills. However, there is presently no vehicle for integrating actions between these directorates, or between municipalities, or between them and the provincial and/or central government.

Being painfully aware of, but not necessarily admitting to, the varying degrees of deficient performance on service delivery, the government accepted two basic approaches to address these deficiencies, as follows:

The first approach is to shift funds, decision making power, responsibilities and accountabilities from central government to local government. This serves to get the people on local and district level, directly involved in the needs and priorities assessment, solution development and implementation. To this end, the Local Government: Municipal Systems Act, 2000, instructs each local authority to draw up an Integrated Development Plan (IDP) by facilitating direct community participation in the needs assessments within its area of jurisdiction (Botha, 2003: 10). The timeframe of an IDP is 5 years. It will henceforth serve to link a municipality's projects (excepting emergency and compliance projects) to its programmes, and from there to its (municipal) strategy. The IDP Guide Pack VI, (2000: 8) as quoted by Botha (2003: 11) states specifically that proper project management must be instituted to make the implementation of an IDP possible.

The second approach is to prescribe in the Local Government: Municipal Systems Act, 2000 thorough procedures and methodologies, with the emphasis on embracing project management. Botha (2003: 9-13) points out that the IDP can be broken down into a number of time and budget bound specific goals, and that most of these goals require a multi-functional and even a multi(governmental) approach. Then he adds onto that the new obligation on municipalities to budget, operate, and measure their performance on the delivery of services, and opines that these considerations can be directly related to the four foundations of project management as discussed earlier. He therefore concludes that a formalised project management approach is eminently suitable to solve the many challenges facing local authorities.

Most of the 284 municipalities in South Africa have found, however, the project way of management and the associated organisational adaptations required, to be significantly different from their traditional functional way of management and the associated bureaucratic inclinations. On contemplating the application of project management, most municipalities found it considerably more difficult to implement than is superficially apparent. Concluding from the above considerations, a well-considered and planned approach to project management implementation seems beyond doubt. 


\section{Preamble to the implementation of project management}

Drawing on the previous discussions, implementing project management in a municipal environment, must therefore provide for all or most of the following aspects:

- $\quad$ developing the systems way of thinking about all adhoc services to be delivered;

- developing an organisational culture of acceptance of cross-functional integration;

- $\quad$ developing comprehensive planning systems;

- willingness of top management to intervene and support the shift to the project way of management;

- the development of an organisation fitted strategy, a project management supportive organisational culture and a customised project management methodology;

- putting the necessary systems and organisational changes in place; and

- ensuring sufficient skill in project management procedures and techniques.

\section{The case study}

This paper reports on a case study, describing the problematics experienced with, and the lessons learnt from the implementation of project management in a district municipality, hereafter referred to as DM. DM covers about 23,000 square $\mathrm{km}$, over spans 7 category B municipalities with a combined population of about 600,000 people. It is also responsible for the technical, administrative and management services of a number of small communities that have not yet developed into fully autonomous category B municipalities. As district municipality it also executes in its area, some of the responsibilities of the Western Cape Provincial Government on an agency basis. DM has become one of the first non-metropolitan municipalities that has established a fully fledged Project office under the management of a Programme manager, who reports directly to the Municipal Manager. This is of course the subject of this paper.

\section{The lessons learnt from implementing project management in DM district municipality}

\section{Top management must be firmly committed}

The first and most basic lesson learnt regarding project management implementation, is that top management must demonstrate its unequivocal and visible support for a transition to the project management way of goal achievement. This was also reported by Krüger and Steyn (1995: 58), on a similar venture. The mentor (see later) advised that this support be communicated to the entire organisation, by way of a clear and unambiguous declaration of intent - a 'lesson' learnt from Graham (1994: 706) - as a formal and official decision of the Municipal Council of DM. Regrettably the continuous and long drawn out changes in the functional and political top management, mainly due to political turmoil, largely cancelled the good effect of the declaration. Continuous refresher training had to be given to ensure the continuous and collective support of the top management, for the shift to project management and the appurtenant actions to be taken.

\section{Project Management Steering Group}

As can be expected, there existed a considerable diversity of opinion on how to implement project management and also what constitute good project management. A Project Management Steering Group (PSG) for the implementation project was established which operated under the auspices of the Municipal Manager's office. Members of this Group included the Municipal Manager, the Programme Manager as head of the project office, the six project managers, four heads of departments and the mentor for the project. The PSG was tasked to develop the procedures, principles, and methodology for the implementation under the guidance of the mentor (see later), as well as to mediate in all conflict situations. Eventually it will also develop a customised project management methodology for DM. This group acted as an integrating factor and is deemed to have played an irreplaceable role in keeping up the interest, and constantly marketing project management to the rest of the organisation, while considerable conflict was threatening to sink the implementation project.

\section{Implementing project management should be a project in own right}

The functional and operational environment of an organisation cannot come to a standstill for the benefit, or on behalf of, any ad-hoc achievement of that organisation. By implication the two must run concurrently. The third lesson learnt was that the only way to achieve this concurrence is to revert to managing the ad-hoc achievement (the implementation) as a project. Thereby a single point of responsibility as well as benchmarking against predetermined measurable outputs, ownership, focus, dedication and structure for the effort, can be established. It also implies that a project leader for the implementation project as such, had to be appointed.

\section{The implementation project should be mentored}

All stakeholders agreed that the project manager for the implementation project must be an internal appointment, so as to enhance buy-in of all staff. The fourth lesson learnt was that based on the low level of knowledge, generally speaking, of project management, a mentor for the designated project manager had to be appointed, with the following duties and responsibilities:

- to act as an independent external advisor to the implementing project leader and team members on project management practices and related matters that may surface during the implementation process; 
- $\quad$ to serve as an external evaluator of the organisation's progress with the implementation of project management;

- $\quad$ to give expert advice to the municipality aligned with world best practices in project management; and

- $\quad$ to facilitate progress assessment meetings on at least a monthly basis and render pertinent guidance on matters arising.

Certain mind shifts to the project management approach need to be promoted amongst the functional staff.

Firstly, staff members had to understand that for the execution and duration of a project, the hierarchy of the functional structures is of very little consequence. Inputs to the implementation project must be solicited from any hierarchical position and level. The project leader occupied a hierarchical position, subordinate to that of some of the inputting elements, yet the project leader is in charge. This "low hierarchy awareness" required considerable motivational effort before being accepted by the senior functionaries.

Secondly, for the team members dual relationships, responsibilities, information flow and instruction taking resulted, - the well known "two-boss" syndrome. Very clear role redefinition for the team members regarding both the horizontal and the vertical reporting had to be maintained at all times.

The third, particularly difficult mind shift that had to be made, was that relating to a project, the specific effort of a (specialist) team member is now not a goal in own right, but becomes subordinate to and in support of the achievement of the team's goal. In other words, functional departments became 'relegated' to suppliers of resources and not 'drivers' of projects.

Most of the functional heads regarded the above as a threat to their authority, because the adjustment in their roles seemingly reduced their ability to control subordinates' activities. However, once they were accustomed to this revised role, productivity generally improved dramatically, because this in fact afforded them the opportunity to exercise their speciality without the daily chores typical of organising projects.

In the fifth instance it became clear quite soon, that the sensitivity and importance of the newly created relationships between the cross-functional and line managers had to be discussed thoroughly and continuously with all the managers at all levels during the implementation of the cross-functional organization.

Lastly, it became evident that such a change in organisational focus to project management as a strategic objective, also impacts on other government institutions and stakeholders with which DM interacts operationally. The need for a dedicated communication process with such stakeholders and associates, prior to and during the implementation project must be emphasized.

\section{Resistance to change}

Nicholas (1990: 481) warns, as confirmed by Knutson (1994: 437), and several other sources, that project management represents a major departure from the traditional business processes of functionally oriented organisations. Resistance to such change is one of the most common phenomena in transformational management according to most sources on organisational development. The sixth lesson learnt, therefore led to the inclusion of a change management process as a sub-project, aimed at the councillors, officials and customers alike, to be included in the project plan. In DM this problem was severally exacerbated by a new municipal government dispensation, that required extensive restructuring and the exchange of several functional responsibilities between the category $\mathrm{B}$ and $\mathrm{C}$ municipalities. This made it quite clear soon that the change management process had to be meticulously managed within the project management implementation project, because management must be in a position to distinguish between resistance to change as a result of the project management implementation or as a result of other internal or political matters impacting on organisational behaviour.

\section{Absence of a team culture}

The seventh lesson learnt relates to an absence of a 'team culture'. This often manifested itself in a prima donna propensity by some of the functional specialists. One characteristic of successful cross-functional teams is that they are indeed participative in nature and allow their members free and equal access to communication (Ford \& Randolph, 1992: 284); by implication then, outside of their own functional 'silo'. This problem was overcome by intensive training regarding the need for, the usefulness and operation of cross-functional structures with heavy emphasis on team building exercises.

\section{Adaptations to the organisation structure}

Municipalities in South Africa hitherto, do not provide for, or even facilitate non-functional management. That means the management of activities outside the jurisdiction of a function. This is, according to Ford and Randolph (1992: 271) contradictory to the basic project management approach, namely that with project management, the project leader has primary control over the resources and the project's direction. Positions had to be created for and authority specifically delegated to the project leaders. The effect was that DM's Delegation Register had to be formally adapted by a resolution of DM Municipal Council, to provide for expenditure authority for the project leaders. Career models for project managers do not exist in municipal organisation structures. A complete design of the performance criteria, career paths and remuneration structures for project managers in DM was necessitated. 


\section{Restructuring of the financial management systems}

Several factors pertaining to conventional, municipal financial management were found to impede on effective project management implementation and functioning. Firstly a lack of, or insufficient incentives to perform on any or all of the typical project management success factors. This corresponds with the experience of Graham (1994: 706, 707). Secondly, until recently all municipalities exercised only zero-based annual budgeting instead of continuous project budgeting, but are now statutorily required to develop multi-year budgets for projects, as and when this will contribute to the more efficient execution of projects. However, this does not include an autonomous activity- and output-based cost management system, and the Municipal Finance Management Act, 2003 also does not provide for it. It is presently not possible to change the prescribed formal budgeting system due to the said act. The ninth lesson learnt, was that a shift from functionally based financial reporting to integrated project based cost reporting is needed, which requires an organisation wide intervention. Such cost reporting systems must be developed to be compatible with the municipality's financial management system(s).

\section{Threat to project managers}

The tenth lesson learnt is about an aspect that was completely overlooked. Namely that the project managers appointed for the various projects of the municipality, felt threatened. They were taken out of their functional roles and thrusted into a new, predominantly managerial role. They were obviously not prepared or adequately trained for those responsibilities. At first, that also did not provide them with the security of a career, due to the project management being in an experimental stage. The efforts required to master the management of projects were initially met with little real enthusiasm, which resulted in the techniques being applied in a haphazard way. Unfortunately this redeployment coincided with a politically driven organisation restructuring which did little to put the minds of the appointed project managers at rest. Cognisance of, and serious attention to this potential disrupting effect, must be built into the process at a very early stage.

\section{Pilot projects to prove desirability of project management}

No evidence could be found in any literature, of any empirical proof that project management is the better approach to goal achievement. It was therefore decided to identify five pilot projects, with carefully selected project leaders, to demonstrate the usefulness of the project way of management; to act as a 'laboratory' to customize the generic approach taught during the project management training, to DM's local circumstances; and to develop the set of rules with which to formalize the project management process and techniques to be applied by DM. The latter became known as the 'blue book' for project management at DM. Even though the 'blue book' is not nearly finished yet (previous experiences indicate about 2 years for such a venture), the pilot projects (the successes and problems) contributed in a major way towards establishing already an informal protocol for DM's project management approach, which are used to guide the project managers on subsequent projects. The role of the mentor is deemed extremely important to act as an 'interface' between customising to DM's specific requirements on the one hand and conforming to accepted generic protocol and best practices and procedures on the other hand.

\section{Conflict resolution}

Project management operates in principle cross-functionally. From the outset conflict over resource allocation and control between line and project managers were omnipresent. It became clear quite early that instituting a conflict resolution procedure should be high on the priorities for the implementation project. This was facilitated by the Project Management Steering Group.

\section{The project schedule}

One of the outcomes and big advantages of the project management approach is that it is subject to establishing a project schedule. This contains details of the activities required to achieve the outcome, the logical sequence of these activities, the estimated duration of each of the activities and therefore of the project as a whole. The schedule also constitutes the workflow of the project and is commonly known as the 'critical path diagram' (CPD) for the project. In essence a CPD represents a systems view of a project showing the elements as well as the interdependencies between the elements. It articulates the project team's view of how the different functional inputs are to be configured to deliver the required output. Such a CPD is clearly worthless if it does not endorse the actions flowing forth from the problematics discussed in the previous sections.

\section{Conclusion}

The lessons learned from this case study about marrying functional, operationally focused management, with crossfunctional, product focused management, can be summarized as follows:

- the interaction (or integration) between departments required to render a cross-functionally produced output successful, does not happen automatically or even as a natural inclination of the members of those departments. Therefore, managing cross-functionally in an organisation has to be 'engineered';

- $\quad$ manage the implementation of project management as a project in own right, complete with activities, resources, schedules and budget;

- $\quad$ authority regarding direction setting, decision-making that affects peoples behaviour and "commandeering" of resources, is imperative for a project of this nature. Therefore the development of the implementation strategy needs visible and stated top management support; 
- $\quad$ attend to the compatibility of the project management systems and software with that of the 'mother organisation';

- there is no empirical proof that the project way of making services available in a local authority is better than the traditional way. Therefore a few pilot projects must be run to demonstrate the better results, as well as being a 'laboratory' to customise the generic project management principles to the local authority's circumstances; and

- a carefully managed change management project to enhance the development of a project management supporting organisational culture, and to facilitate the migration from functions thinking to process thinking must run concurrent with the implementation project.

\section{References}

Bonelli, G. 1998. 'Implementing a project management discipline’, Austin Business Journal, 18(19).

Botha, M. C. 2003. 'Formulating and implementing a strategy for project management in the Eden District Municipality'. Unpublished dissertation for the MBA degree, University of Stellenbosch Business School, Bellville.

Brown, C. J. 1999. 'Towards a strategy for project management implementation', South African Journal of Business Management, 29(4).

Brown, C. J. 2000. 'The dimensions of a project management supporting organisational culture'. Paper presented at the World Project Management Week Conference, Cairns, Australia, 8 - 11 October.

Brown, C. J. 2004. 'Study guide for the Programme in Project Management'. Unpublished course material for the MBA degree, International School of Management, Dortmund, Germany.

Constitution of the Republic of South Africa. 1996. Pretoria: Government printer.

Ford, R. C. \& Randolph, W. A. 1992. 'Cross-functional structures: A review and integration of matrix organisation and project management', Journal of Management, 18(2):267 - 294.

Graham, R. J. 1994. 'Leading the change to project management'. Paper presented at the PMI $25^{\text {th }}$ Annual Seminar, Vancouver, Canada, 17 - 19 October.

IDP guide pack vi. 2000. Pretoria: Government Printer.

Kerzner, H. 1992. Project management: A systems approach to planning, scheduling and controlling. $4^{\text {th }}$ edition. New York: Wiley, USA.

Kezsbom, D. S. \& Edward, K. A. 2001. The new dynamic project management. $2^{\text {nd }}$ edition. New York: Wiley \& Sons.
Knutson, J. 1994. 'The top management steering committee'. Paper presented at the PMI $25^{\text {th }}$ annual seminar, Vancouver, Canada, 17 - 19 October.

Krüger, L. P. \& Steyn, G. P. 1995. 'The success factors in the implementation of project management in public sector works departments', Management Dynamics, 4(4):49 - 68.

Local Government: Municipal Structures Act, 1998. Pretoria: Government Printer.

Local Government: Municipal Systems Act, 2000. Pretoria: Government Printer.

Morrison, J. M. \& Brown, C. J. 2004. 'Project management effectiveness as a construct: A conceptual study', South African Journal of Business Management, 35(4).

Municipal Financial Management Act, 2003, Pretoria: Government Printer.

Nicholas, J. M. 1990. Managing business and engineering projects: Concepts and implementation. Englewood Cliffs, New York, USA: Prentice Hall.

Reiss, G. 1992. Project management demystified. London: E \& FN Spon.

Tettemer, J. M. 1991. Keeping your bosses happy while implementing project management - a management view, Guide to the PMBOK. Pennsylvania, USA: PMI, Drexel Hill. 